\title{
Electroless Ni-P/PTFE Self-Lubricating Composite Thin Films Applied for Medium-carbon Steel Substrate
}

\author{
Hung-Hua Sheu ${ }^{1, *}$, Shun-Yi Jian ${ }^{1}$, Ming-Hsien Lin ${ }^{1}$, Chih-I. Hsu ${ }^{2}$, Kung-Hsu Hou ${ }^{2}$, Ming-Der Ger ${ }^{1, *}$ \\ ${ }^{1}$ Department of Chemical and Materials Engineering, Chung Cheng Institute of Technology, National \\ Defense University, Taoyuan City, Taiwan \\ ${ }^{2}$ Department of Power Vehicle and Systems Engineering, Chung Cheng Institute of Technology, \\ National Defense University, Taoyuan City, Taiwan

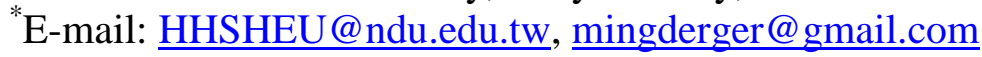

doi: $10.20964 / 2017.06 .30$

Received: 5 March 2017 / Accepted: 25 April 2017 / Published: 12 May 2017

\begin{abstract}
Generally, the linear guide (made by medium-carbon steel) ways are operated under lubricated conditions. The external lubricants such as grease and oil will evaporate easily, thus, the re-lubrication is necessary. The electroless deposition technique is utilized to deposit a layer of self-lubricating NiP/PTFE composite coating with a uniform thickness about $5 \mu \mathrm{m}$ onto the medium-carbon steel substrate in this study. The effect of PTFE concentration in the plating bath on the deposition rate, corrosion resistance, hardness, hydrophobicity and wear behavior of the composite coatings are studied. The results show that the hardness as well as the friction coefficient of composite coatings decreases with the increase of incorporated PTFE content in the coating. It results in the wear rate of the Ni-P/PTFE composite coating first decreases with the increase of PTFE content in the coating and then increases with the PTFE content. Heat treatment at $400^{\circ} \mathrm{C}$ is found to have significant effect on the wear properties of Ni-P/PTFE coating. The friction coefficient of composite coatings increases after heat treatment at $400^{\circ} \mathrm{C}$ due to the decomposition of PTFE. The wear test result shows that the friction coefficient of medium-carbon steel substrate reduces from 0.07 to 0.035 after deposition a layer of Ni-P/PTFE composite coating on it.
\end{abstract}

Keywords: self-lubrication; composite coatings; Ni-P/PTFE; medium-carbon steel substrate; electroless deposition

\section{$\underline{\text { FULL TEXT }}$}

(C) 2017 The Authors. Published by ESG (www.electrochemsci.org). This article is an open access article distributed under the terms and conditions of the Creative Commons Attribution license (http://creativecommons.org/licenses/by/4.0/). 